กORTH CLIn IStanB 2018;5(1):31-36

doi: $10.14744 /$ nci.2017.58855

\title{
Sleep quality and anxiety level in employees
}

\author{
Ayse Gulsen Teker, ${ }^{1}$ Nimet Emel Luleci ${ }^{2}$ \\ ${ }^{1}$ Health Directorate, Nigde, Turkey \\ ${ }^{2}$ Department of Public Health, Marmara University Faculty of Medicine, Istanbul, Turkey
}

\begin{abstract}
OBJECTIVE: The aim of this study was to measure the sleep quality and anxiety level of a group of employees, as well as determine the relationship between sleep quality and anxiety and other factors.

METHODS: A total of 130 of 185 employees at a university campus were enrolled in this cross-sectional study. A descriptive questionnaire, the Pittsburgh Sleep Quality Index, and the Beck Anxiety Inventory were the data collection instruments. In addition to univariate analysis, the relationship between the 2 scales was examined with Spearman correlation analysis.

RESULTS: Of the participants, $38.9 \%$ had poor sleep quality. Gender, income level, presence of a chronic disease, regular medication use, and relationship with family and the social environment were found to affect both sleep quality and anxiety. A decrease in sleep quality was associated with an increase in the level of anxiety.

CONCLUSION: Poor sleep quality and a high anxiety level are common in this country, as in the rest of the world. Socioeconomic interventions and psychosocial support to improve the status of individuals with risk factors, such as chronic disease, will reduce anxiety and improve sleep quality and overall psychosocial health. Further prospective studies should be conducted with different groups of participants and with larger samples to expand knowledge of the relationship between sleep quality and anxiety.
\end{abstract}

Keywords: Anxiety; anxiety disorders; occupational health; public health; sleep; sleep-wake disorders.

Se leep-wake disorders are divided into 10 types of disorder or group of disorders that encompass a wide spectrum. More than 100 disorders have been defined [1]. Sleep-wake disorders cause complaints related to the timing, quality, and quantity of sleep. All sleep-wake disorders lead to insufficient sleep and reduced daily performance [2]. The most frequently seen sleep-wake disorder is difficulty falling sleep and staying asleep [3]. Sleep-wake disorders are common. In the USA alone, 50 to 70 million people suffer from a sleep-wake disorder [4]. It has been reported that these disorders affect $20 \%$ to $30 \%$ of the general population, and in some studies the incidence rate was as high as $37 \%[5,6]$.

Though sleep-wake disorders are not unusual, they often go uninvestigated. They are directly related to an individual's health status, are a major factor in morbidity, and are associated with increased mortality. They are also associated with increased susceptibility to the common cold [7].

In addition to physical health effects, sleep-wake disorders are closely related to a regression in psychomotor functions, and people with sleep-wake disorders are more likely to have an accident [8]. It has also been found that absenteeism is greater patients with sleepwake disorders, they experience difficulty concentrating, have weaker job performance, and a greater probability of experiencing a workplace accident [6]. The effect of productivity loss and increased healthcare expenditures related to sleep-wake disorders was reported to be an annual cost of $\$ 30$ to 35 billion in the USA, with total

Received: June 29, 2017 Accepted: August 16, 2017 Online: January 18, 2018

Correspondence: Dr. Ayse Gulsen TEKER. Nigde Saglik Mudurlugu, Nigde, Turkey.

Tel: +903882120011 e-mail: agulsenteker@hotmail.com

(c) Copyright 2018 by Istanbul Provincial Directorate of Health - Available online at www.northclinist.com 
direct costs for insomnia estimated to be $\$ 13$ billion [9].

A close relationship between sleep-wake disorders and mental disorders has been demonstrated in many studies. Anxiety disorders, the most common class of mental disorder, are associated with the severity and chronicity of sleep-wake disorders [10]. Common features of anxiety disorders include excessive fear and worry, which can lead to behavioral disorders [2]. In a systematic review, the 1 -year and lifetime prevalence rate of anxiety disorders was found to be $10.6 \%$ and $16.6 \%$, respectively [11]. In another survey, individuals with insomnia were found to be 17.35 times more likely to have clinically significant anxiety [12]. In a study performed with 14915 participants, about $28 \%$ of those with insomnia had a current diagnosis of a mental disorder and $25.6 \%$ had a psychiatric history. Past or present anxiety disorders were the most frequently seen mental disorders in association with insomnia [13].

The number of studies investigating the incidence rate of sleep-wake and anxiety disorders in this country is very limited. Saracoglu et al. [14] found that $10.4 \%$ of the study population reported daytime sleepiness, and that there was a significant and positive correlation between daytime sleepiness and anxiety risk. The most recent, reliable study on the epidemiology of anxiety disorders in Turkey was performed in 1998, and the researchers found that $6.7 \%$ of the participants had received a diagnosis of an anxiety disorder in the previous year [15].

Both sleep quality and anxiety level are important, in terms of both the effects on the health of the individual and quality of life, as well as the effects on the health of an employee, the health of the community, and the healthcare system. The objective of this study was to determine the sleep quality and anxiety level of a group of employees, and to examine the correlation between them, as well as other factors.

\section{MATERIALS AND METHODS}

Approval for this cross-sectional study was obtained from the ethics committee of the Marmara University Faculty of Medicine (no. 09.2014.0318). The study participants were advised about the research both orally and in writing, and informed consent was obtained.

\section{Sampling}

The participants in this research were employees of a university. At the time of the study, a total of 185 employees worked at the university campus. With an assumption of $50 \%$ poor sleep quality, for a $95 \%$ confidence interval with a $5 \%$ margin of error, an adequate sample size was calculated to be 126 employees. Shift workers were not included.

\section{Data collection tools}

Questionnaires and scales completed by volunteer participants were used to collect the study data.

\section{Descriptive questionnaire}

The investigators prepared a questionnaire containing 29 questions related to the sociodemographic characteristics of the study participants.

\section{Pittsburgh Sleep Quality Index}

The Pittsburgh Sleep Quality Index (PSQI) was developed by Buysse et al. [16]. Validation and reliability studies were conducted by Ağargün et al. in 1996, and the Cronbach's alpha coefficient for reliability was 0.80 [17]. The PSQI provides information about sleep quality and the type and severity of sleep-wake disorders experienced within the previous month. The scale consists of a total of 24 questions; 19 answers are provided by the participant and 5 by his/her bed partner or roommate, when present. Only the self-rated responses are included in the assessment. The PSQI consists of 7 components (subjective sleep quality rating, sleep latency, sleep duration, habitual sleep efficiency, sleep disturbances, use of sleeping medication, and daytime dysfunction) that each yield a score of 0 to 3 . The sum of the 7 component scores is the global PSQI score. A total score of 5 or greater indicates a poor sleeper; the disruption to sleep quality is worse as the PSQI score increases.

\section{Beck Anxiety Inventory}

The Beck Anxiety Inventory (BAI) measures the frequency of anxiety symptoms experienced by the individual. It is a Likert-type self-assessment consisting of 21 items, each scored between 0 and 3. The maximum total score is 63 points. A greater total score indicates increased anxiety. The scale was developed by Beck et al. [18] in 1988. Validation and reliability of the Turkish version was conducted by Ulusoy et al. 19 in 1998, with a Cronbach's alpha reliability coefficient of 0.93 .

\section{Statistical analysis}

SPSS for Windows, Version 15.0 (SPSS, Inc., Chicago, IL, USA) was used to evaluate the study data. Descriptive findings were expressed as numbers, percentiles, and means. The data were not normally distributed; there- 
fore, for intergroup comparisons of measurable values, the Mann-Whitney $U$ test and the Kruskal-Wallis test were applied. Correlation between the 2 scales was evaluated using Spearman correlation analysis. $\mathrm{P}<0.05$ was accepted as the level of statistical significance.

\section{RESULTS}

\section{Individual characteristics of the participants}

An adequate sample was achieved with a total of 130 participants: 89 (68.5\%) women and 41 (31.5\%) men. The mean age of the study population was $36.6 \pm 10$ years (range: 18-63 years). The education level of the group was university $(\mathrm{n}=105 ; 80.8 \%)$, high school $(\mathrm{n}=10 ; 7.7 \%)$, middle school $(n=5 ; 3.8 \%)$, and primary school $(n=10$; $7.7 \%)$. The participants were married ( $n=82 ; 63.1 \%)$, single $(n=41 ; 31.5 \%)$, and separated/divorced $(n=7 ; 5.4 \%)$. There were instructors $(\mathrm{n}=27 ; 20.8 \%)$, research workers $(n=41 ; 31.5 \%)$, office-workers $(n=29 ; 22.3 \%)$, laborers $(\mathrm{n}=16 ; 12.3 \%)$, nurses $(\mathrm{n}=7 ; 5.4 \%)$, and employees with other professions $(n=5 ; 3.8 \%)$ included.

In the study population, $82.2 \%$ lived with family and $13.2 \%$ lived alone. While $54.6 \%$ of the participants had children, $45.4 \%$ did not. The question "Does your income meet your expenses?" was responded to affirmatively by $50.8 \%$ of the participants and negatively by $49.2 \%$.

\section{Sleep quality and anxiety scale scores}

The PSQI and BAI scores are presented in Table 1. The mean overall PSQI scale score was $5.6 \pm 3.3$ (range: $0-17)$. The PSQI score of $38.9 \%$ of the participants was $>5$ points, which indicates poor sleep quality.

The mean BAI score of all of the respondents was $8.6 \pm 9.9$ (range: $0-53$ ).

When the scores were compared according to gender, the anxiety level of the female participants was significantly higher $(p=0.044)$. The mean and median BAI scores of female participants were 9.76 and 5.5, respectively, while the corresponding scores of male participants were 5.05 and 4.0, respectively. Sleep quality was not statistically significantly different between genders $(p=0.323)$. The group of patients who had difficulty meeting their expenses had both poor sleep quality and higher anxiety levels $(p=0.002$ and $p=0.001$, respectively). Age, education level, vocation, and marital status were not statistically significantly correlated with either sleep quality $(p=0.783, p=0.609, p=0.956$, and $p=0.065$, respectively) or anxiety level $(p=0.969$, $\mathrm{p}=0.074, \mathrm{p}=0.578$, and $\mathrm{p}=0.522$, respectively).

The BAI score of participants who regularly used medication and/or had a chronic disease was found to

TABLE 1. The Pittsburgh Sleep Quality Index and Beck Anxiety Inventory scores of the participants according to their individual characteristics

\begin{tabular}{|c|c|c|c|c|c|c|}
\hline & \multicolumn{3}{|c|}{ Pittsburgh Sleep Quality Index } & \multicolumn{3}{|c|}{ Beck Anxiety Inventory } \\
\hline & Median & Min-max & $\mathrm{P}$ & Median & Min-max & $\mathrm{P}$ \\
\hline \multicolumn{7}{|l|}{ Gender } \\
\hline Female & 5.0 & $0.0-17.0$ & & 5.5 & $0.0-53.0$ & \\
\hline Male & 3.0 & $2.0-13.0$ & 0.323 & 4.0 & $0.0-29.0$ & 0.044 \\
\hline \multicolumn{7}{|l|}{ Income level } \\
\hline Meets expenses & 4.0 & $0.0-15.0$ & & 3.0 & $0.0-24.0$ & \\
\hline Does not meet expenses & 6.0 & $1.0-17.0$ & 0.001 & 6.0 & $0.0-53.0$ & 0.007 \\
\hline \multicolumn{7}{|l|}{ Chronic disease } \\
\hline Yes & 5.0 & $1.0-17.0$ & & 8.0 & $0.0-53.0$ & \\
\hline No & 5.0 & $0.0-15.0$ & 0.299 & 4.0 & $0.0-46.0$ & 0.02 \\
\hline \multicolumn{7}{|l|}{ Regular use of medication } \\
\hline Yes & 5.50 & $1.0-17.0$ & & 14.5 & $0.0-53.0$ & \\
\hline No & 5.0 & $0.0-15.0$ & 0.081 & 4.0 & $0.0-45.0$ & 0.02 \\
\hline \multicolumn{7}{|l|}{ Known sleep disorder } \\
\hline Yes & 10.0 & $4.0-15.0$ & & 14.5 & $0.0-53.0$ & \\
\hline No & 4.0 & $0-17.0$ & $p<0.001$ & 4.0 & $0.0-46.0$ & 0.002 \\
\hline
\end{tabular}


TABLE 2. The Pittsburgh Sleep Quality Index and Beck Anxiety Inventory scores of the participants according to their relationship with their family/members of household and social environment

\begin{tabular}{|c|c|c|c|c|c|c|c|c|c|c|}
\hline & \multicolumn{5}{|c|}{$\begin{array}{l}\text { Pittsburgh Sleep Quality Index } \\
\text { (median/min-max) }\end{array}$} & \multicolumn{5}{|c|}{$\begin{array}{l}\text { Beck Anxiety Inventory } \\
\text { (median/min-max) }\end{array}$} \\
\hline & Very good & Good & Moderate & Bad & $\mathrm{p}$ & Very good & Good & Moderate & Bad & $\mathrm{p}$ \\
\hline Relationship with & $4.5 /$ & $5.0 /$ & $7.5 /$ & - & & $3.0 /$ & $5.0 /$ & $19.0 /$ & - & \\
\hline family/ members & $0.0-$ & $0.0-$ & $4.0-14.0$ & & 0.013 & $0.0-$ & $0.0-$ & $2.0-53.0$ & & $<0.001$ \\
\hline of household & 15.0 & 17.0 & & & & 46.0 & 30.0 & & & \\
\hline Relationship & $3.5 /$ & $5.0 /$ & $5.0 /$ & 11.0 & & $4.0 /$ & $4.0 /$ & $12.0 /$ & 9.0 & \\
\hline with social & $0.0-$ & $0.0-$ & $2.0-14.0$ & & 0.045 & $0.0-$ & $0.0-$ & $0.0-53.0$ & & 0.005 \\
\hline environment & 13.0 & 17.0 & & & & 46.0 & 34.0 & & & \\
\hline
\end{tabular}

TABLE 3. Correlation Analysis of the Pittsburgh Sleep Quality Index and the Beck Anxiety Inventory*

\begin{tabular}{lcccccccc} 
& $\begin{array}{c}\text { Subjective } \\
\text { sleep quality }\end{array}$ & $\begin{array}{c}\text { Sleep } \\
\text { latency }\end{array}$ & $\begin{array}{c}\text { Sleep } \\
\text { duration }\end{array}$ & $\begin{array}{c}\text { Habitual sleep } \\
\text { efficiency }\end{array}$ & $\begin{array}{c}\text { Sleep } \\
\text { disturbances }\end{array}$ & $\begin{array}{c}\text { Use of sleeping } \\
\text { medication }\end{array}$ & $\begin{array}{c}\text { Daytime } \\
\text { dysfunction }\end{array}$ & $\begin{array}{c}\text { Total PSQI } \\
\text { score** }\end{array}$ \\
\hline BAI & $r=0.471$ & $r=0.299$ & $r=0.089$ & $r=0.216$ & $r=0.446$ & $r=0.111$ & $r=0.433$ & $r=0.480$ \\
score & $p<0.001$ & $p=0.001$ & $p=0.326$ & $p=0.016$ & $p=<0.001$ & $p=0.219$ & $p<0.001$ & $p<0.001$ \\
\hline
\end{tabular}

*Spearman correlation analysis.

BAI: Beck Anxiety Inventory; PSQI: Pittsburgh Sleep Quality Index.

be statistically significantly higher ( $p=0.02$ for both). However, their PSQI scores did not differ significantly $(\mathrm{p}=0.081)$.

Participants known to have a sleep disorder had poorer sleep quality $(p<0.001)$ and a higher anxiety level $(p=0.02)$. However, there was not a significant difference in the sleep quality $(p=0.354)$ or the anxiety level $(p=0.595)$ between participants with a known psychiatric problem and those without. Similarly, the sleep quality $(p=0.071)$ and the anxiety level $(p=0.120)$ of patients with a history of psychiatric illness did not differ significantly from those without.

The participants were asked to classify their relationship with their family/members of the household as very good, good, moderate, or bad, and a significant correlation was found between the state of participants' relationships and sleep quality $(\mathrm{p}=0.013)$ as well as anxiety level $(p<0.001)$. Favorable social relationships were associated with better sleep quality and less anxiety. The same relationship was seen with regard to connection to the social environment and the participant's sleep quality $(\mathrm{p}=0.045)$ and anxiety level $(\mathrm{p}=0.005)$ (Table 2$)$.
Results of correlation analysis of the Pittsburgh Sleep Quality Index and the Beck Anxiety Inventory

The association between the total PSQI, the 7 component PSQI scores, and BAI scores was analyzed using the Spearman rank correlation coefficient. Correlation analysis indicated that BAI scores were statistically significantly but only moderately correlated with subjective sleep quality, sleep disturbances, daytime dysfunction, and total PSQI score, while BAI scores were statistically significantly but weakly correlated with sleep latency and habitual sleep efficiency (Table 3). These results demonstrate that a deterioration in sleep quality increases anxiety and/or an increase in anxiety worsens sleep quality.

\section{DISCUSSION}

In the present study, $38.9 \%$ of the participants had poor sleep quality. In previous studies conducted in our country, poor sleep quality was detected in $41.1 \%$ to $53.2 \%$ of the participants [20-22]. Research performed abroad 
indicated an incidence rate of poor sleep quality between $32.5 \%$ and $57.5 \%$ [23-25].

Our investigation revealed a higher anxiety level in female participants; however, a correlation between gender and sleep quality was not found. Similarly, previous studies failed to find a correlation between gender and sleep quality [20, 23, 25]. However, James et al. [23] indicated that female gender was associated with a risk for bad sleep quality. Consistent with the literature, no correlation between sleep quality and age, education level, profession, or marital status was found in our survey $[23,25]$.

Research has not determined a correlation between income level and sleep quality and anxiety. However, in this study, sleep quality and anxiety were worse in individuals who could not meet their expenses. Lower socioeconomic status constitutes a disadvantage with regard to sleep quality and anxiety level, as is the case with many aspects of health. As indicated by Acheson et al. [26], improvement in individual socioeconomic status will lead to improvement in public health indicators.

In this survey, poorer sleep quality and a higher level of anxiety were detected in participants known to have a sleep-wake disorder, which is consistent with literature findings [20].

According to the results of our research, anxiety was greater in participants with a chronic disease and users of medication; however, no significant difference was found in sleep quality. James et al. [23] and Tirgari et al. [25] both reported a greater incidence rate of anxiety and sleep-wake disorders in individuals with chronic disease and those who use medication. In these surveys, the authors emphasized that chronic disease and continued use of medication constituted a risk for poor sleep quality. Therefore, in cases of chronic disease, psychological care should be part of the overall treatment plan and these individuals should be periodically evaluated by health professionals [26].

Our data also suggest that changes in sleep quality and anxiety level were related to the state of the individual's relationship with his/her family and social environment: good relationships were associated with improved sleep quality and a lower anxiety level. Dogan et al. [28] demonstrated that anxiety decreased with increases in the level of perceived social support. Efforts to increase the level of social support for individuals will positively change their psychosocial well-being.

Previous investigations have analyzed and noted a relationship between sleep-wake disorders and anxiety disorders. In this investigation, an association was found between poor sleep quality and increased anxiety. Kara et al. [29] found a positive correlation between improvement in anxiety and sleep quality.

In conclusion, a significant level of poor sleep quality was detected in this study of employees in our community. Gender, income level, presence of chronic disease, regular use of medication, and the quality of relationships with family and the social environment were found to affect sleep quality and anxiety level. Ameliorative interventions targeting socioeconomic conditions and psychosocial care for the individuals with risk factors, such as chronic disease, will improve sleep quality and general psychosocial health, and decrease anxiety levels. Poor sleep quality has been found to be associated with increased anxiety. However, larger, prospective, in-depth investigations with diverse groups should be performed.

Conflict of Interest: No conflict of interest was declared by the authors.

Financial Disclosure: The authors declared that this study has received no financial support.

Authorship contributions: Concept - A.G.T., N.E.L.; Design A.G.T., N.E.L.; Supervision - A.G.T., N.E.L.; Materials - A.G.T., N.E.L.; Data collection \&/or processing - A.G.T., N.E.L.; Analysis and/or interpretation - A.G.T., N.E.L.; Writing - A.G.T., N.E.L.; Critical review - A.G.T., N.E.L.

\section{REFERENCES}

1. Kumar VM. Sleep and sleep disorders. Indian J Chest Dis Allied Sci 2008;50:129-35.

2. American Psychiatric Association. Diagnostic and Statistical Manual of Mental Disorders. 5th ed. Arlington: American Psychiatric Association; 2013.

3. Hilty D, Young JS, Bourgeois JA, Klein S, Hardin KA. Algorithms for the assessment and management of insomnia in primary care. Patient Prefer Adherence 2009;3:9-20. [CrossRef]

4. Senthilvel E, Auckley D, Dasarathy J. Evaluation of sleep disorders in the primary care setting: history taking compared to questionnaires. J Clin Sleep Med 2011;7:41-8.

5. Arroll B, Fernando A 3rd, Falloon K, Goodyear-Smith F, Samaranayake C, Warman G. Prevalence of causes of insomnia in primary care: a cross-sectional study. Br J Gen Pract 2012;62:e99-103. [CrossRef]

6. Morphy H, Dunn KM, Lewis M, Boardman HF, Croft PR. Epidemiology of insomnia: a longitudinal study in a UK population. Sleep 2007;30:274-80.

7. Pigeon WR, Heffner K, Duberstein P, Fiscella K, Moynihan J, Chapman BP. Elevated sleep disturbance among blacks in an urban family medicine practice. J Am Board Fam Med 2011;24:161-8. [CrossRef]

8. Lee M, Choh AC, Demerath EW, Knutson KL, Duren DL, Sherwood RJ, et al. Sleep disturbance in relation to health-related quality of life in adults: the Fels Longitudinal Study. J Nutr Health Aging 2009;13:576-83.

9. Walsh JK, Engelhardt CL. The direct economic costs of insomnia in the 
United States for 1995. Sleep 1999;22 Suppl 2:S386-93.

10. Staner L. Sleep and anxiety disorders. Dialogues Clin Neurosci 2003;5:249-58.

11. Somers JM, Goldner EM, Waraich P, Hsu L. Prevalence and incidence studies of anxiety disorders: a systematic review of the literature. Can J Psychiatry 2006;51:100-13. [CrossRef]

12. Taylor DJ, Lichstein KL, Durrence HH, Reidel BW, Bush AJ. Epidemiology of insomnia, depression, and anxiety. Sleep 2005;28:1457-64.

13. Ohayon MM, Roth T. Place of chronic insomnia in the course of depressive and anxiety disorders. J Psychiatr Res 2003;37:9-15. [CrossRef]

14. Saracoglu GV, Tokuc B, Dogan S, Celikkalp U, Saracoglu A. Frequency of Daytime Sleepiness and Risk of Anxiety and Depression Among Shift Workers in Two Selective Factories. Turk J Public Health 2015;13:206-16.

15. Erol N, Kılıç C, Ulusoy M, Keçeci M, Şimşek Z. Türkiye Ruh Sağlığı Profili Raporu. 1. bask1. Ankara: 1998; p. 81.

16. Buysse DJ, Reynolds CF 3rd, Monk TH, Berman SR, Kupfer DJ. The Pittsburgh Sleep Quality Index: a new instrument for psychiatric practice and research. Psychiatry Res 1989;28:193-213. [CrossRef]

17. Agargun MY, Kara H, Anlar O. Pittsburgh Sleep Quality Index Validity and Reliability. Turk Psikiyatri Dergisi 1996;7:107-15.

18. Beck AT, Epstein N, Brown G, Steer RA. An inventory for measuring clinical anxiety: psychometric properties. J Consult Clin Psychol 1988;56:893-7. [CrossRef]

19. Ulusoy M, Şahin NH, Erkmen H. Turkish Version of the Beck Anxiety Inventory: Psychometric Properties. J Cogn Psychother 1998;12:163-72.

20. Sari OY, Uner S, Buyuakkus B, Bostanci EO, Celiksoz AH, Budak M.
Sleep Quality and Some Factors Affecting Sleep Quality in the Students Living in the Residence Hall of a University. TAF Prev Med Bull 2015;14:93-100. [CrossRef]

21. Üstün Y, Çınar Yücel Ş. The Investigation of Sleep Quality of Nurses. Maltepe Universitesi Hemsirelik Bilim ve Sanat Dergisi 2011;1:29-38.

22. Aktas H, Sasmaz CT, Kilincer A, Mert E, Gulbol S, Kulekcioglu D. Study on the Factors Related to Physical Activity Levels and Sleep Quality in Adults. Mersin Univ Saglik Bilim Derg 2015;8:60-70.

23. James BO, Omoaregba OJ, Igberase OO. Prevalence and correlates of poor sleep quality among medical students at a Nigerian university. Ann Nigerian Med 2011;5:1-5. [CrossRef]

24. Lemma S, Patel SV, Tarekegn YA, Tadesse MG, Berhane Y, Gelaye B, et al. The Epidemiology of Sleep Quality, Sleep Patterns, Consumption of Caffeinated Beverages, and Khat Use among Ethiopian College Students. Sleep Disord 2012;2012:583510. [CrossRef]

25. Tirgari B, Forouzi MA, Iranmanesh S, Shahraki SK. Predictors of Sleep Quality and Sleepiness in the Iranian Adult: A population Based Study. Journal of Community Health Research 2013;1:144-52.

26. Acheson D, Alleyne GA, Casas JA, Castillo-Salgado C, Barzach M, Braveman $\mathrm{P}$, et al. Round table discussion. Health inequalities and the health of the poor. Bull World Health Organ 2000;78:75-85.

27. Özdemir Ü, Taşcı S. Psychosocial Problems and Care of Chronic Diseases. Erciyes Üniversitesi Sağllk Bilimleri Fakültesi Dergisi 2013;1:57-72.

28. Doğan T. Psikolojik Belirtiler, Sosyal Destek ve İyilik Hali. Türk Psikolojik Danısma ve Rehberlik Dergisi 2008;3:30-44.

29. Kara N. Sleep Disturbance, Psychopathology, and Quality of Life. Arch Neuropsychiatr 2016;53:102-7. [CrossRef] 